\begin{tabular}{ccc}
\hline & International Journal of Engineering \& Technology, $7(2.33)(2018) 409-415$ \\
SPC & International Journal of Engineering \& Technology \\
Website: $w$ ww.sciencepubco.com/index.php/IJET & Research paper \\
\hline
\end{tabular}

\title{
Optimization of dc-bus voltage regulation with grid con-nected single phase bi-directional converter
}

\author{
V. N. Ganesh ${ }^{1 *}$, J. Ajay Daniel ${ }^{1}$, D. Sivakumar ${ }^{1}$, S. Balaji ${ }^{1}$ \\ ${ }^{1}$ Assistant Professor, EEE Department SRM Institute of Science \& Technology, Ramapuram, Chennai, Tamil Nadu \\ *Corresponding author E-mail: vnganesh15@gmail.com
}

\begin{abstract}
This paper presents using of alternate input energy source for optimization of DC bus voltage regulation and maintaining of availability of DC bus voltage with grid connected single phase bi-directional converter. Power generated by PV system and DC-DC boost converter with MPPT technology and fuzzy logic control for DC applications. Excess power available in the solar panel will return back to AC grid. DC power will be drawn from the AC grid when the intensity of sun is less. Maximum power output is obtained by using MPPT technique from PV panel. FUZZY controller is also used along with MPPT to control the final DC output voltage regulation of solar panel connected to the DC bus and for smooth power transfer. Simulation and actual experiments results are shared in detail for the implementation of MPPT with FUZZY controller and the modes of operation of Bi-directional converter.
\end{abstract}

Keywords: Photovoltaic System; MPPT with Fuzzy Control; Boost Converter; Bidirectional Converter with Boost Operation; DC Load; AC Load.

\section{Introduction}

In major European countries DC power is used instead of AC power because of the above mentioned problem. But this system also have a drawback of dc-bus voltage regulation getting affected, when more load variation in DC distribution system take place. So proper management have to be done for power sharing and to maintain DC bus voltage regulation.

Solar power is used as the input along with grid connected bidirectional converter which is connected to AC source are helpful for DC bus voltage regulation and power stability is explained using Fuzzy controller technique on MPPT. Bi-directional converter is helpful in regulating DC voltage, reducing the cost and to obtain harmonies ac/dc distribution system. When the output from the solar panel is higher than the required output bi-directional converter injects the increased power into AC grid that is said to be grid-connected approach. In other words, the rectifier yield power from the AC grid to compensate the DC load requirement, which is defined as rectification mode.

To trail the highest power point of the solar panel output the MPPT control is used and to have best voltage regulation, the Fuzzy logic control is additionally added along with MPPT control which controls boost converter to maintain dc bus voltage within targeted or expected value . For study purpose, the DC bus voltage considered here is $50 \mathrm{~V} \mathrm{dc}$. Modes of operation of bidirectional converter are inversion and rectification mode.

When there is broad variation in the AC grid supply $(230 \mathrm{~V}+10 \%$ and $-11 \%$ ), the bidirectional converter needs to works as boost converter to get expected dc bus voltage when the input ac grid voltage is below certain level. Similarly step down or Buck converter operation is needed when the input ac grid voltage is above certain level. Under rectification mode operations, boost functionality has been studied and explained in this paper with simulation results.

\section{System configuration and design}

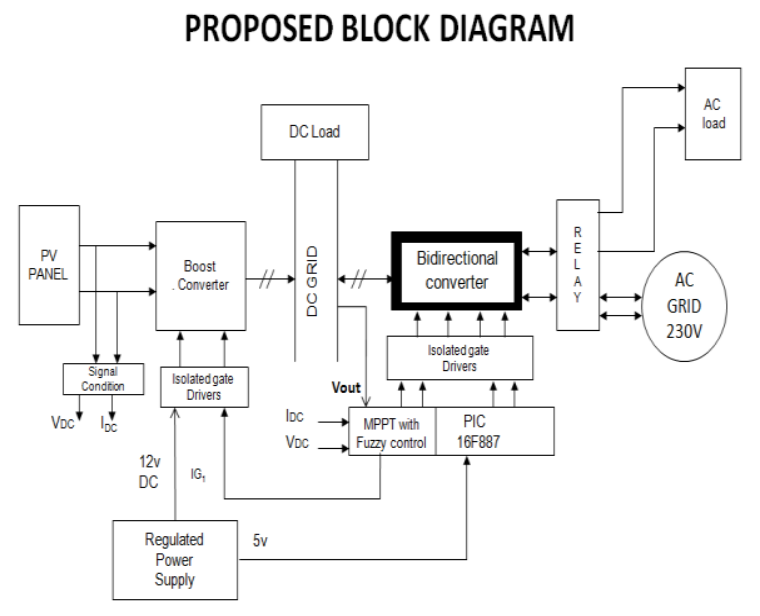

Fig. 1: Proposed System Configuration.

Fig. 1 shows the proposed scheme in which the PV solar panel output is connected to the input of boost converter and the boost converter output connected to the dc grid. In typical application, the nominal voltage of the dc bus is $380 \mathrm{~V} \mathrm{dc}$. DC load is connected across the dc grid. Bidirectional converter using $\mathrm{H}$-bridge converter configuration is connected between dc grid and ac grid, ac load. Relay is used to control supply goes to ac load.

VDC is solar panel output voltage sensing signal. IDC is solar panel output current. It goes to control section where the MPPT with fuzzy control will follow the maximum power point of the solar panel and to control the output voltage of the boost converter or dc bus voltage within set value. Perturb and observe MPPT algorithm 
is used for maximum power point tracking purpose. Isolated gate drive is used to trigger the boost converter switch with controlled PWM signal comes from the MPPT/Fuzzy controller with galvanic isolation. Thus complete power and control section of solar dc output to dc grid has been designed. H-Bridge bidirectional converter using MOSFET is connected between de grid and ac grid. When solar panel output is healthy, the surplus power output of solar panel will be transferred to ac grid and ac load through bi directional converter by operating it as inverter by keeping dc grid voltage within targeted range. This is called "selling or grid connected mode". When solar panel output goes below certain level due to less solar energy, the power and dc voltage level of the dc grid will be sourced and maintained from the ac grid through bi directional converter by operating it as rectifier. This is called "rectification mode".

\section{Implementation of MPPT with fuzzy to con- trol solar output boost converter}

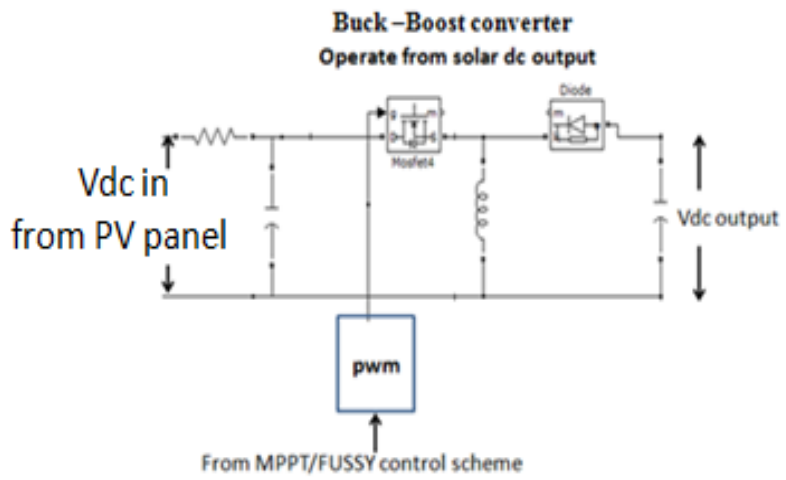

$\mathrm{V}_{\mathrm{o}}=\left[\frac{-\mathrm{D}}{1-\mathrm{D}} \mathrm{V}_{\mathrm{dc}}\right.$ input $]$

$\mathrm{D}=\frac{\mathrm{T}_{\text {on }}}{\mathrm{T}_{\text {on }}+\mathrm{T}_{\text {off }}}$

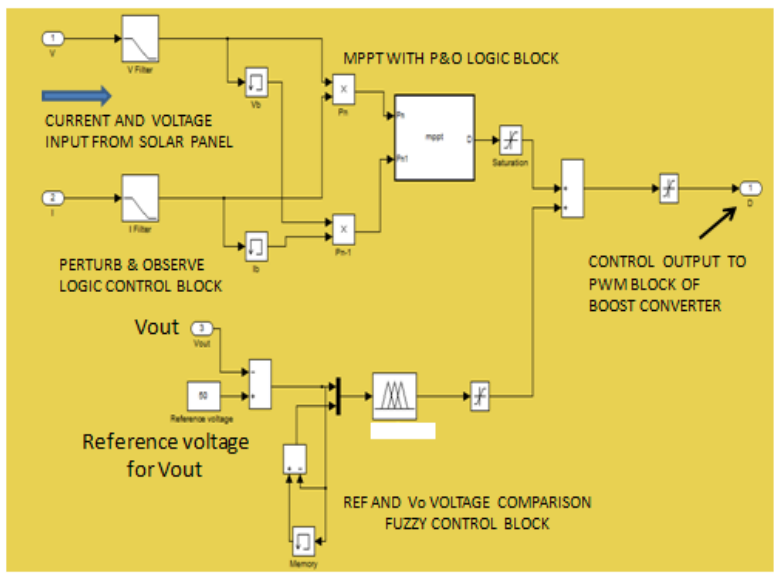

Fig. 2: Boost Converter Control Scheme with MPPT with Fuzzy Control.

Fig. 2 shows the simulation diagram of boost converter control scheme portion of solar panel output in which MPPT with Fuzzy control technique is implemented. Maximum power point tracking is done by using perturb \& observe ( $\mathrm{P} \& \mathrm{O})$ algorithm .Solar panel output current and voltage are sensed and given as input signals to the control block as shown. Using P\&O MPPT algorithm, the power level of latest and previous output of solar panel are estimated and net control signal is generated from the MPPT control block. DC bus reference voltage and actual output of dc bus voltage are compared and error and change in error are used as two independent inputs to fuzzy controller as shown in the figure. Output of the fuzzy controller is summed with output of MPPT controller and final duty ratio controlled control signal is generated which goes to PWM block to produce gate drive pulses to switch boost converter
MOSFET . Output of the boost converter is controlled de voltage connected to dc bus. In this paper, design is made to have $50 \mathrm{~V}$ constant dc voltage across dc bus. But actual dc bus voltage is $380 \mathrm{~V}$ nominal in practical application. DC bus voltage regulation is better and tighter when controlling boost converter using combination of MPPT with Fuzzy logic control.

\section{Implementation of fuzzy control}

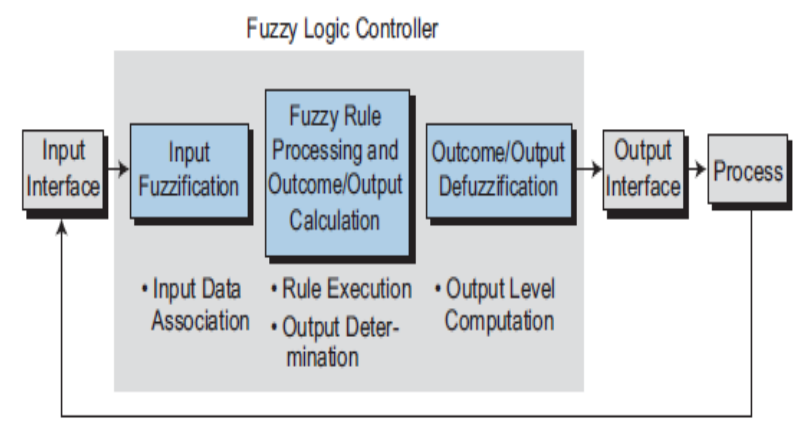

Fig. 3: Basic Fuzzy Logic Control Block.

Fig. 3 shows basic fuzzy logic controller scheme. In various industrial applications; fuzzy controller is one of the famous controllers used in a wide range. The process of fuzzy logic controller strategy contains fuzzification, decision making and defuzzification.

i) Fuzzification is the progression on behalf of the responses as suitable linguistic variable

ii) Decision Making is castoff for suitable control action to carried out. It is based on the information base and rule base. Knowledge base and rule base are the details about the linguistic variables and control rules

iii) Defuzzification is the method of altering fuzzified output into crisp value.

Fuzzy Logic Algorithm:

Below is the procedural steps to implement fuzzy control techniques.

A: State linguistic Variables and terms

B: Paradigm the membership functions

C: Paradigm Rule base

D: Transform crisp data to fuzzy values by

Membership function.

E: Estimate rule in the rule base

F: Combine the outcome of each rule

G: Transform output data to non fuzzy or crisp value

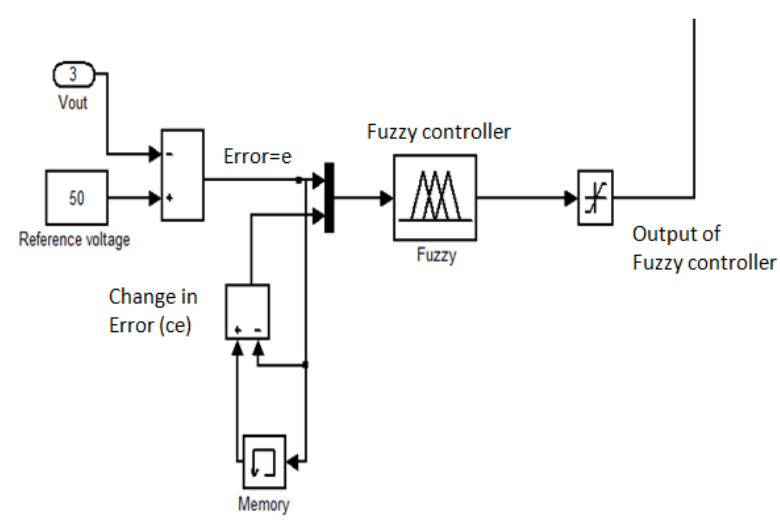

Fig. 4: Fuzzy Controller with Input/Output Signals.

Fig. 4 shows the fuzzy control scheme used in the project to control the solar output boost converter in order to regulate the dc bus voltage. Vout is dc bus voltage and reference voltage is $50 \mathrm{~V}$ which is target value of dc bus voltage. Difference between two inputs is error (e) and difference between current error and previous error is change in error (ce). Both error and change in error signals are the input to fuzzy controller. Output of fuzzy controller is crisp output which is summed with output of MPPT controller. Summation of 
both control output signal gives final control signal which controls boost converter. The following details show the step by step procedure and set up made in the MATLAB simulation tool to implement functionality of fuzzy control.

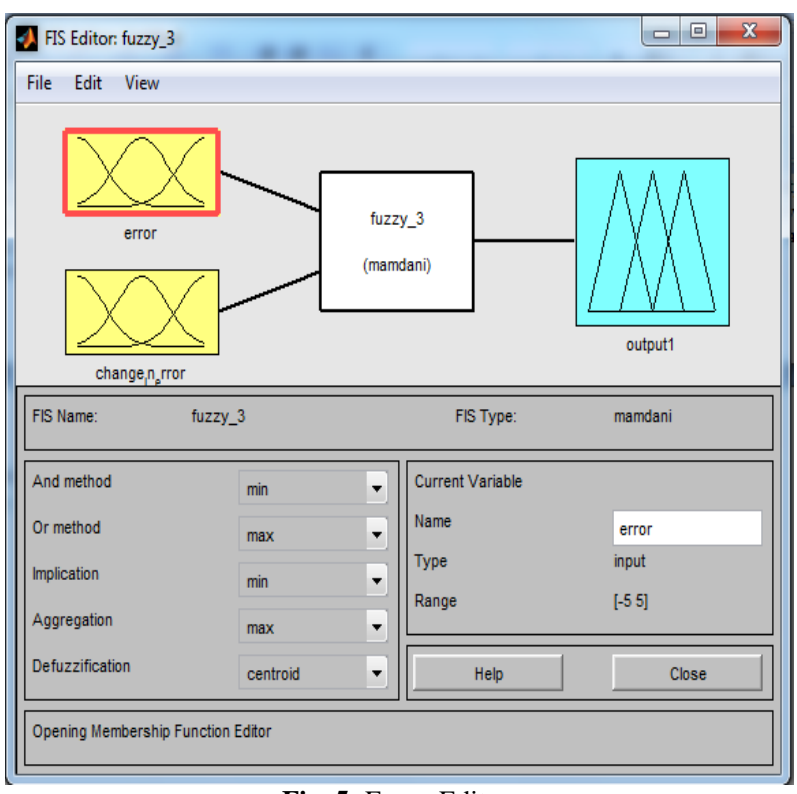

Fig. 5: Fuzzy Editor.

Fig .5 shows error input and change in error input in the form of membership chart which are interfaced with fuzzy controller as the input data.

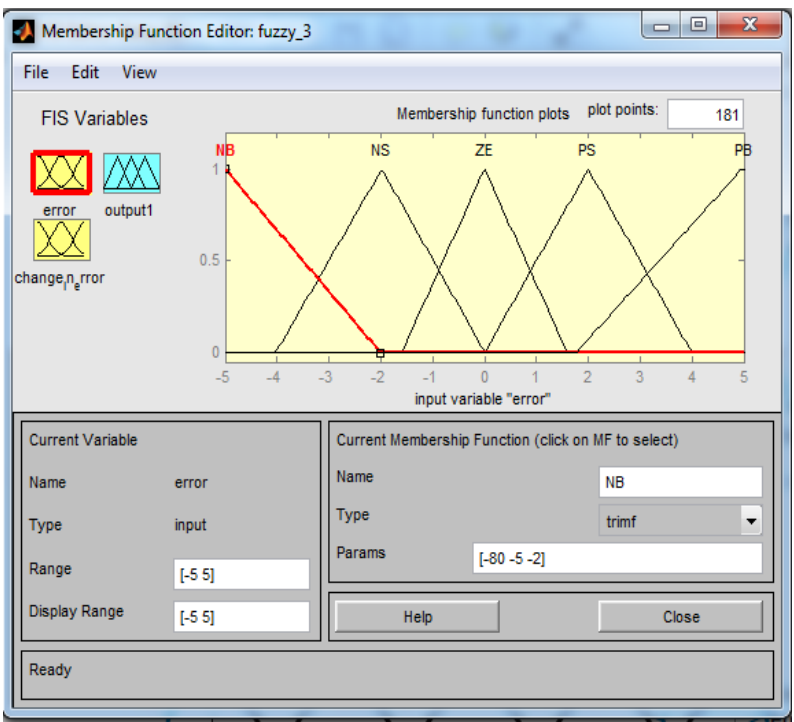

Fig. 6: Membership Function Editor -Error Input.

Fig.6 shows membership function plot of "error "input signal. Triangle member ship function is used to indicate error input signal. Error input signal classified into five membership functions with five membership labels. $\mathrm{X}$-axis of the membership chart indicates range of input signal or input variable which is -5 to +5 . Y-axis indicated membership grade from 0 to 1 range. The input data a grade ranges between 0 to 1 based on how comfortably it accommodates into every membership function.

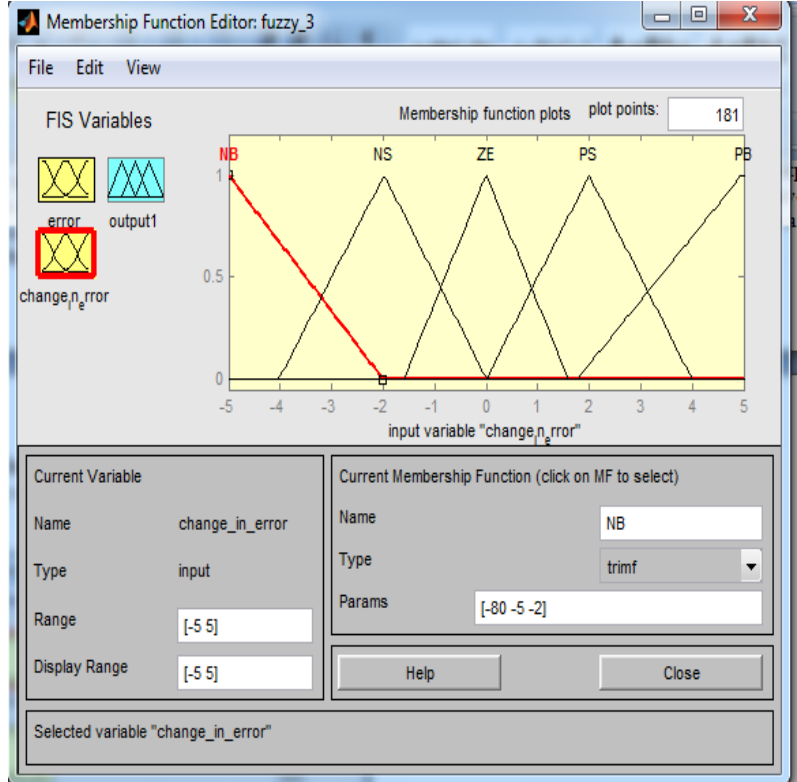

Fig. 7: Membership Function Editor -Change in Error Input.

Error and change in error are having independent membership label of 5 types which are as follows. The difference is between negative big to positive big.

NB - Negative big,

NS - Negative small

ZE - Zero,

PS - Positive small,

PB - Positive big

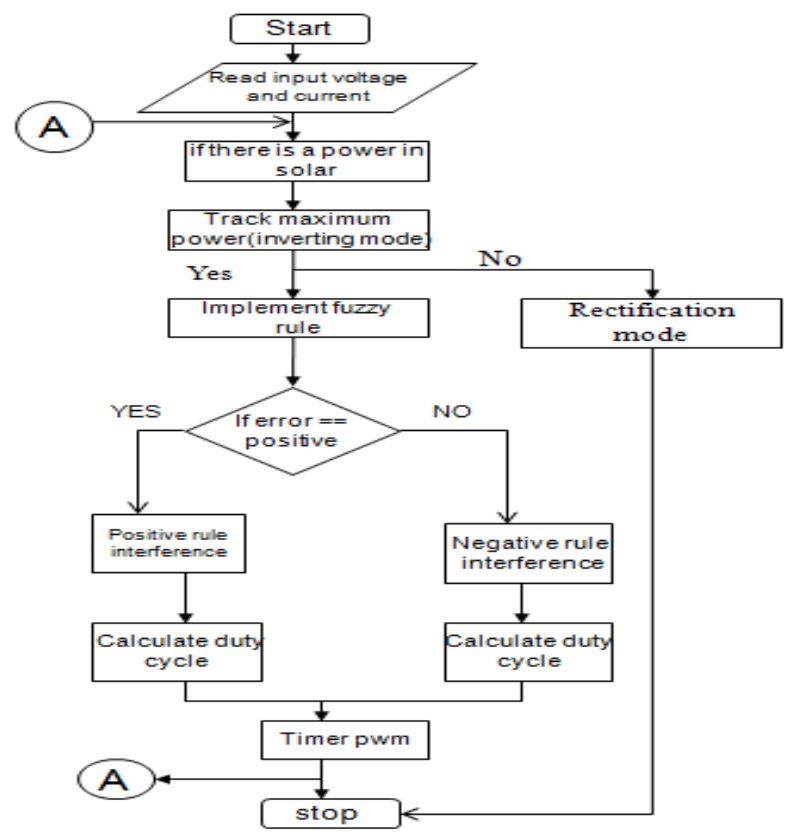

Fig. 8: Overall Control Flow Chart.

Fig.8 shows flow chart of fuzzy control and its step by step approach in controlling duty ratio of the gate pulse of boost converter and maintaining of dc bus voltage regulation. When the solar output is available and it is at maximum power point level, the fuzzy control comes into action. If the error is positive, the positive rule will be applied otherwise the negative rule will be applied in order to generate duty cycle controlled output signal. The duty ratio controlled output signal of the MPPT cum fuzzy control block is used as input to PWM block and it is compared with the carrier signal of 5KHZ.Thus gate drive PWM pulse will be generated to drive boost converter MOSFET. Under this condition the bidirectional converter will be operating as inverter. When the solar panel output is 
not at healthy level, the bi directional converter will operate as rectifier and dc bus voltage will be supplied from the ac grid.

Formation of fuzzy set of rules is done based on the number of sub sets of universe of discourse or membership label or section. In this project, there are 5 subsets and the total number of rule is $(5 \times 5) 25$. More number of sub sets will have more number of rules and more rules will increase accuracy of the system performance but complexity of the control scheme will also increase.

Fuzzy Logic Rule matrix

\begin{tabular}{|llllll|}
\hline \multicolumn{5}{|c|}{ Fuzzy Rule Matrix } \\
\hline (Error) & $\Delta e$ & (change in Error) \\
\cline { 2 - 6 } e & NB & NS & ZE & PS & PB \\
\hline NB & ZE & NS & NB & NB & NB \\
NS & PS & ZE & NS & NS & NB \\
ZE & PB & PS & ZE & NS & NB \\
PS & PB & PS & PS & ZE & NS \\
PB & PB & PB & PB & PS & ZE \\
\hline
\end{tabular}

Fig. 9: Fuzzy Logic Rule Matrix.

Fig.9 shows the matrix form of Fuzzy rules. Error input (e) has its five member ship functions (NB, NS, ZE, PS, PB) and Change in error input has its five membership functions same as error input. So totally there are 25 set of rules formed.

1. If (error is NB) and (change_in_error is NB) then (output1 is ZE) (1)
2. If (error is NB) and (change_in_error is NS) then (output1 is NS) (1)
3. If (error is NB) and (change_in_error is ZE) then (output1 is NB) (1)
4. If (error is NB) and (change_in_error is PS) then (output1 is NB) (1)
5. If (error is NB) and (change_in_error is PB) then (output1 is NB) (1)
6. If (error is NS) and (change_in_error is NB) then (output1 is ZE) (1)
7. If (error is NS) and (change_in_error is NS) then (outputt is NS) (1)
8. If (error is NS) and (change_in_error is ZE) then (output1 is NB) (1)
9. If (error is NS) and (change_in_error is PS) then (output1 is NS) (1)
10. If (error is NS) and (change_in_error is PB) then (output1 is NB) (1)
11. If (error is ZE) and (change_in_error is NB) then (output1 is PB) (1)
12. If (error is ZE) and (change_in_error is NS) then (output1 is PS) (1)
13. If (error is ZE) and (change_in_error is ZE) then (output1 is ZE) (1)
14. If (error is ZE) and (change_in_error is PS) then (output1 is NS) (1)
15. If (error is ZE) and (change_in_error is PB) then (output1 is NB) (1)
16. If (error is PS) and (change_in_error is NB) then (output1 is PB) (1)
17. If (error is PS) and (change_in_error is NS) then (output1 is PS) (1)
18. If (error is PS) and (change_in_error is ZE) then (output1 is PS) (1)
19. If (error is PS) and (change_in_error is PS) then (output1 is ZE) (1)
20. If (error is PS) and (change_in_error is PB) then (output1 is NS) (1)
21. If (error is PB) and (change_in_error is NB) then (output1 is PB) (1)
22. If (error is PB) and (change_in_error is NS) then (output1 is PB) (1)
23. If (error is PB) and (change_in_error is ZE) then (output1 is PB) (1)
24. If (error is PB) and (change_in_error is PS) then (output1 is PS) (1)
25. If (error is PB) and (change_in_error is PB) then (output1 is ZE) (1)

Fig. 10: Fuzzy Logic Rules.

Fig .10 shows 25 numbers of different fuzzy rules using IF and THEN statement using “AND” operator.

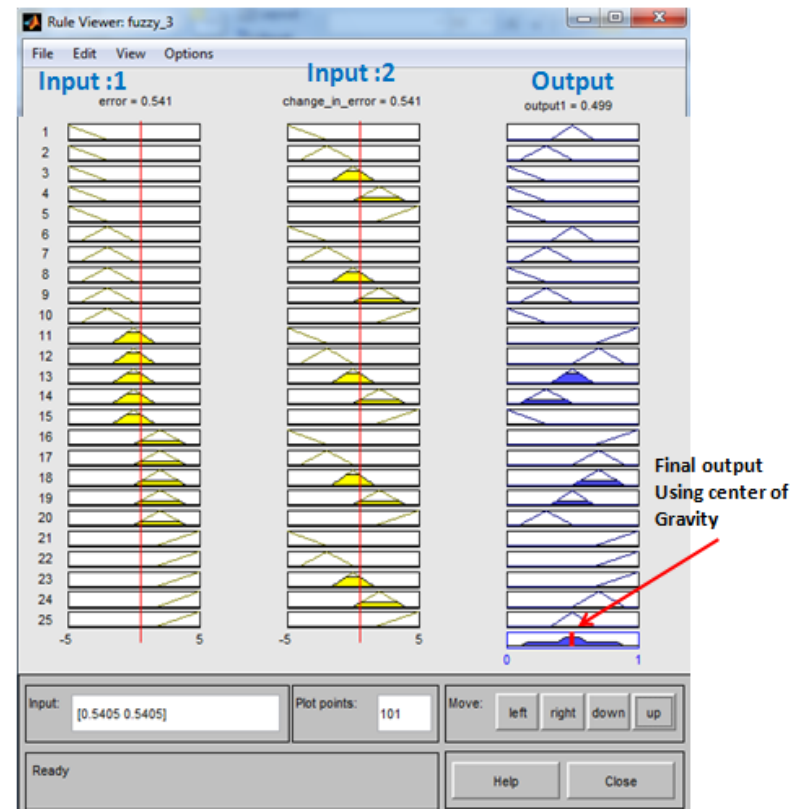

Fig. 11: Pictorial Form of Fuzzy Logic Rules with Two Inputs and Fina Output of Fuzzy Controller.

Example of output generation:

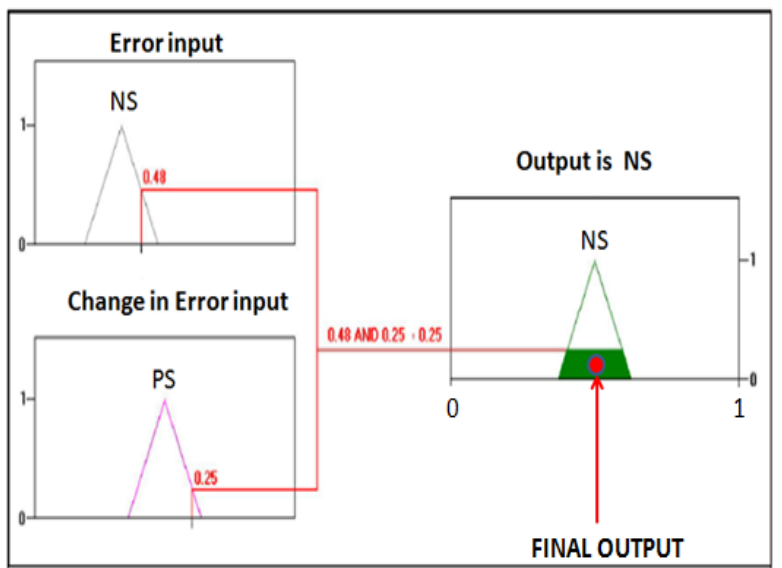

IF (error is NS) AND (change in error is PS) THEN (output is NS)

Fig. 12: Execution of One Rule -Example.

In the Fig.12, based on the input error signal, the particular subset of membership function will be selected along with its membership grade. (0.48).Similarly based on the change in error input signal, the particular subset of its membership function will be selected along with its grade. (0.25). Since AND operator is used, the minimum of two grade points will be used to find output value. As per fuzzy rule shown under the image and corresponding to minimum value $(0.25)$, area will be selected in the NS subset of the output membership as shown. Using centre of gravity method, final output of FLC (Fuzzy Logic Control) will be generated.

Fuzzy final output: The end result of the fuzzy controller based on defuzzification method used to calculate the outcome values with respect to each label. The defuzzification process evaluates all the rule outcomes after they have logically added and then calculates a value that will be the end result of the controller. 


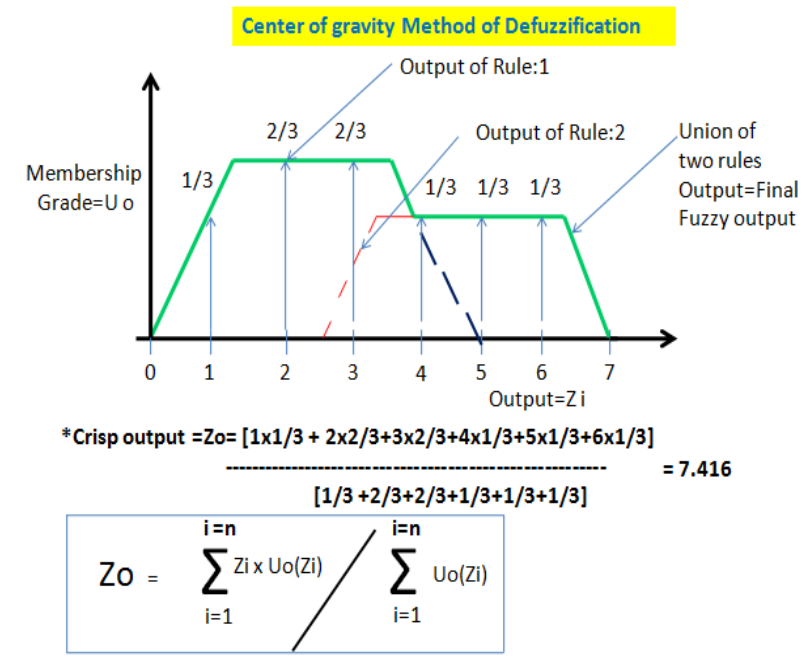

Fig. 13: Execution of Two-Rule System -Example.

Fig.13 shows two -Rule system defuzzification and final fuzzy output arrival formula and method .Conversion of this final fuzzy output to crisp output is defined as defuzzification.

\section{Single phase bidirectional converter}

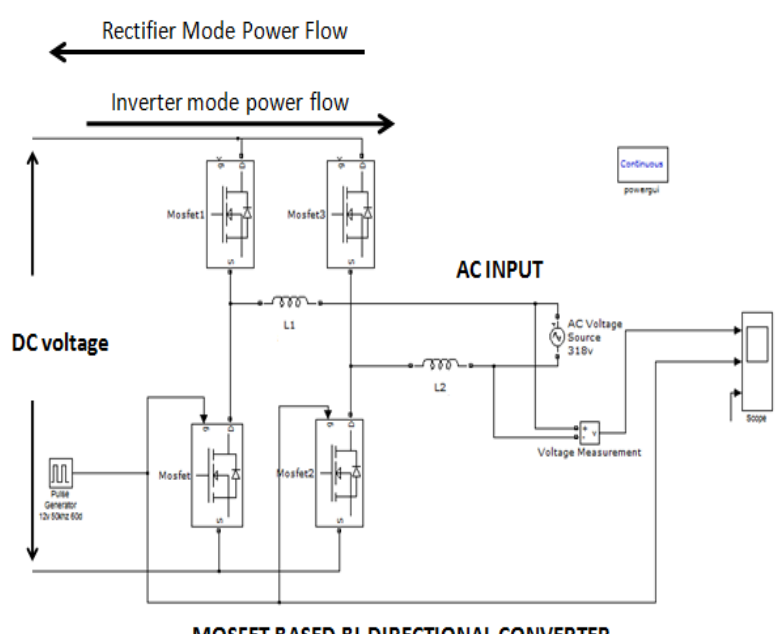

Fig. 14: H-Bridge Bidirectional Converter.

Fig.14 shows H-bridge converter using MOSFET which can be used as either rectifier or inverter and can transfer power in both direction as shown in figure. In this project, bidirectional converter works as inverter by transferring power from solar panel output to the ac grid and ac load when solar output power is excessive after supplying dc load. It also works as rectifier by transferring power from ac grid to the dc bus when the solar power goes low below certain level.

In the rectification mode operation, when use only body diode, the converter output will be uncontrolled one. To control the rectifier output voltage, need to use switch used (MOSFET/IGBT) in the HBridge and control it by controlling duty cycle of the gate pulse. In general, in rectification mode converter will be used as boost converter to have expected output dc voltage across dc bus when the input ac grid voltage is below required level to generate dc bus voltage.

When operating bi directional converter in the rectification mode, the input ac grid voltage variation needs to be considered. When 360 to $400 \mathrm{~V}$ is the operating range of DC bus in a $1 \phi$ system, the input ac rms voltage minimum required is $255 \mathrm{~V}$. But as per electricity standard or in developing countries (India), practical ac grid voltage variation is $230 \mathrm{~V}+/-10 \%$ and even worst in rural area. Under this broad ac grid input voltage variation, in order to meet dc voltage range (Nominal voltage $380 \mathrm{~V}$ ), the rectifier need to work as boost converter or need to boost input voltage to dc bus expected voltage level. Paper present output result of bidirectional converter in the rectification mode for two extreme input voltage levels (207V and $253 \mathrm{~V})$.

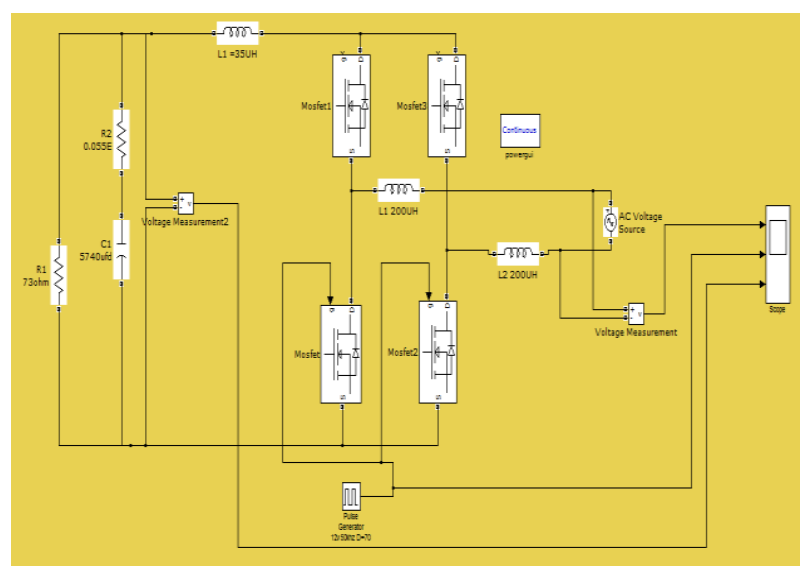

Fig. 15: MATLAB Simulation Diagrambi-Directional Converter as Rectifier \& Inboost Mode.

Top: Input ac voltage $207 \mathrm{~V}$ rms.

Middle: Gate pulse of Bottom MOSFET ( $\mathrm{D}=55 \%, 50 \mathrm{KHZ})$

Bottom: DC bus voltage $380 \mathrm{~V}$

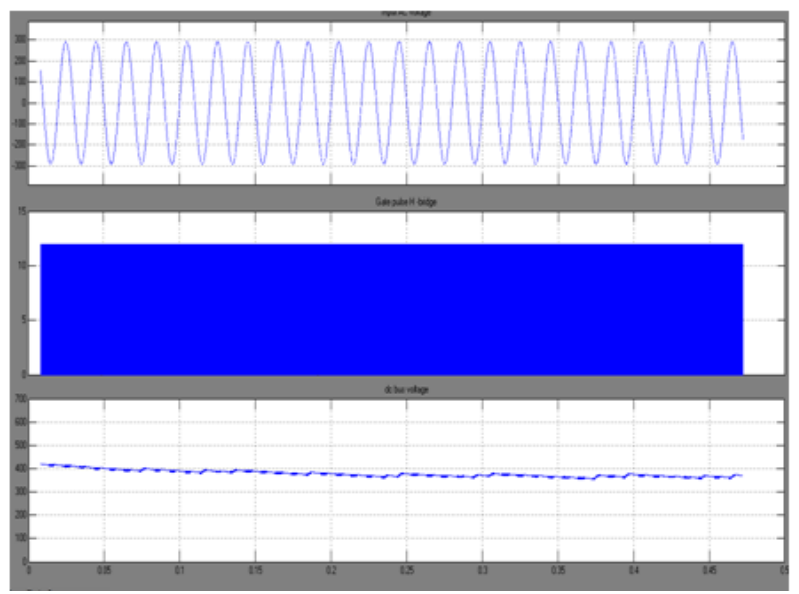

Fig. 16: Rectifier Mode 230V - 10\% Input Ac.

Top: Input ac voltage $253 \mathrm{~V}$ rms.

Middle: Gate pulse of Bottom MOSFET ( $\mathrm{D}=40 \%, 50 \mathrm{KHZ})$

Bottom: DC bus voltage 400V.

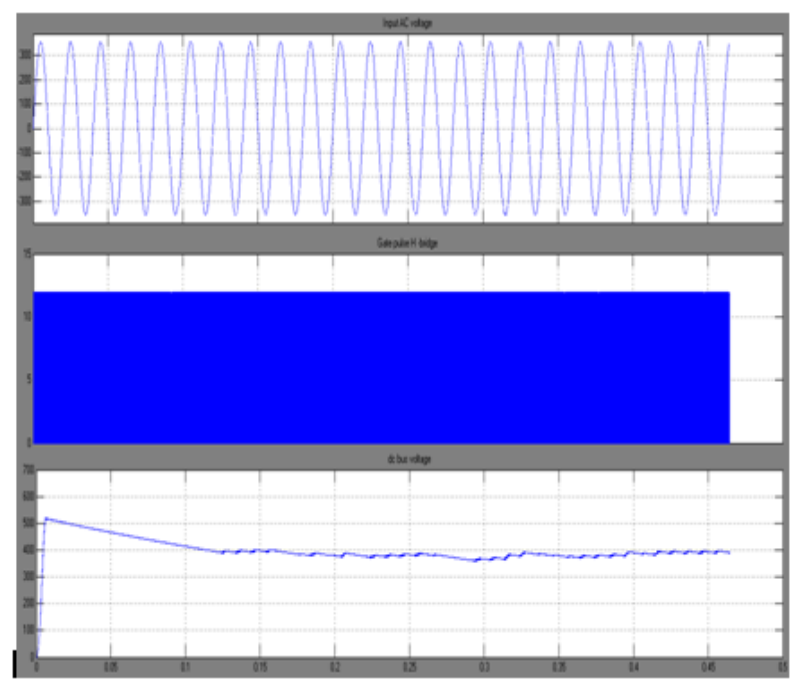

Fig. 17: Rectifier Mode 230V +10\% Input Ac. 
From Fig .15, in the rectification mode, there will be distortion in the input current due to high frequency switching which will be limited by input inductor. Results shows are in open loop condition by setting duty cycle manually. During boost mode operation, only bottom two MOSFETs will be in conduction mode and top two MOSFET will have zero gate signal .Body diode of top MOSFET will transfer power from input to dc bus when bottom MOSFET is at OFF state . Input inductor store energy when bottom MOSFET at $\mathrm{ON}$ state and the stored energy and input source will charge the dc bus capacitor when bottom MOSFET goes OFF state.

Bi-directional converter in inverter mode operation:

In the inverter mode operation, any one type of ac output will be generated of square wave, quasi square wave or sine wave using sinusoidal pulse width modulation (SPWM) technique. Output total harmonics distortion (THD) of voltage will be depended on the type of PWM technique used and switching frequency of inverter.

\section{Actual mat lab simulation study}

Fig.18 and Fig .19 given in next page shows complete MATLAB simulation diagram of the project and internal logic diagram of MMPT with Fuzzy control used for controlling solar panel output dc-dc buck -boost converter. Below are the actual electrical input and output parameter used for simulation study.

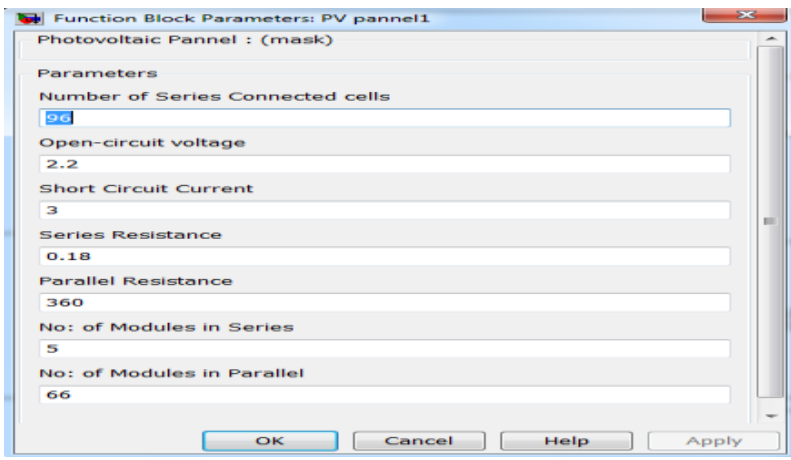

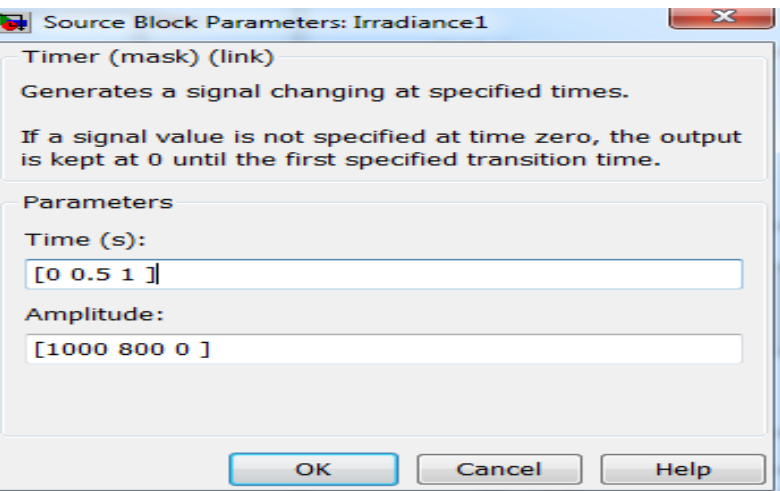

Actual simulation design specification:

a) Reference of DC bus voltage or expected value: $50 \mathrm{~V} \mathrm{dc}$

b) Boost converter switching frequency: $5 \mathrm{KHZ}$

c) $\mathrm{AC}$ voltage input used during rectification mode $=50 \mathrm{~V}$ Peak.

d) AC voltage across AC load or grid during inverter Mode $=50 \mathrm{~V}$ peak, $50 \mathrm{HZ}$, Square wave output.

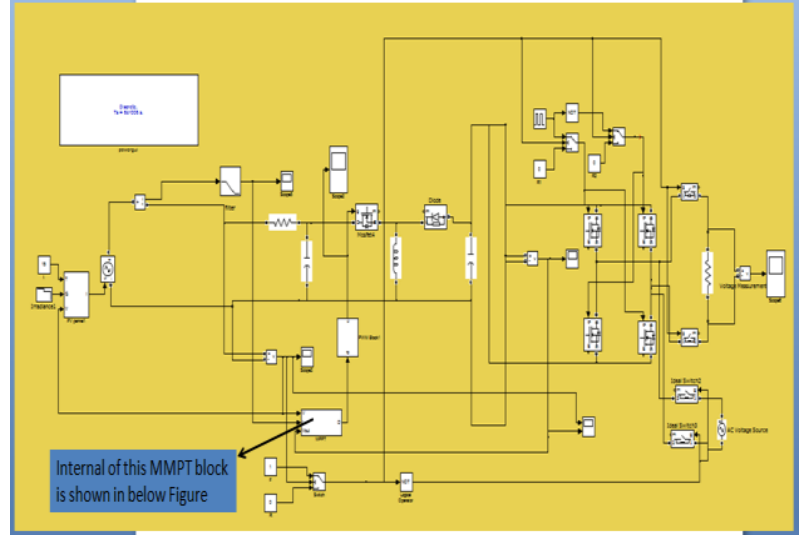

Fig. 18: Complete MATLAB /SIMULINK Diagram.

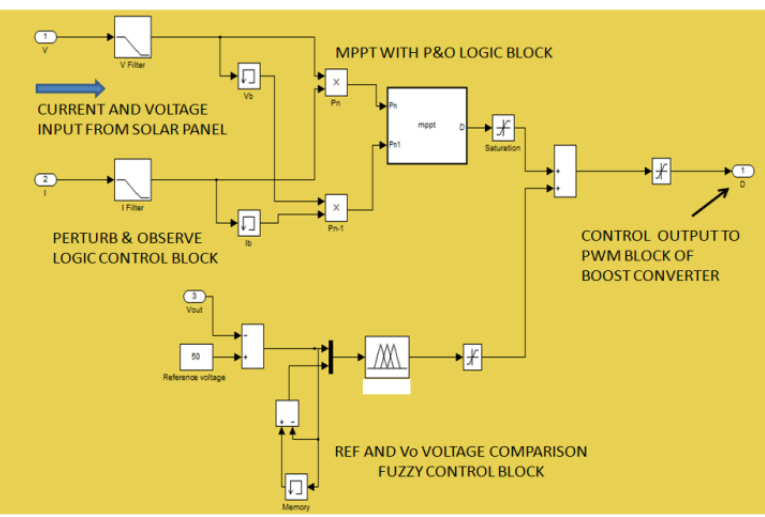

Fig. 19: MPPT with Fuzzy MATLAB Simulation.

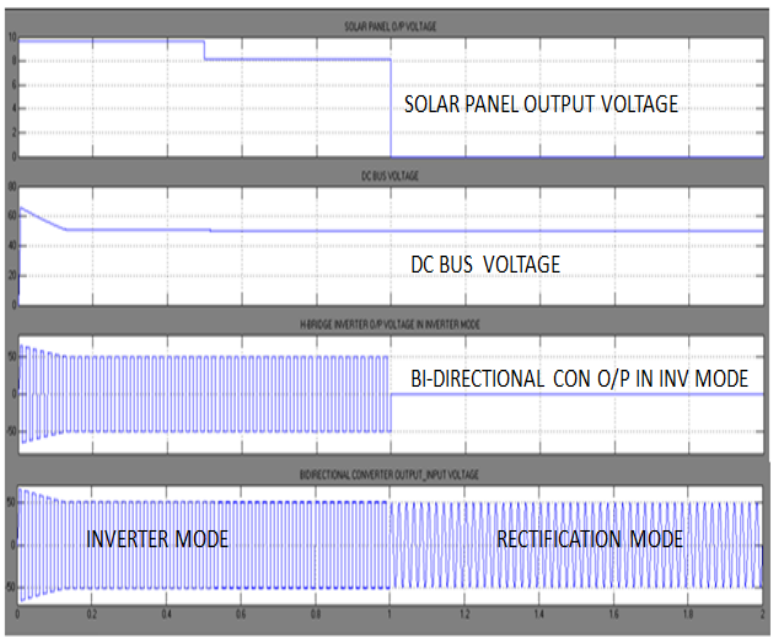

Fig. 20: MATLAB Simulation Output.

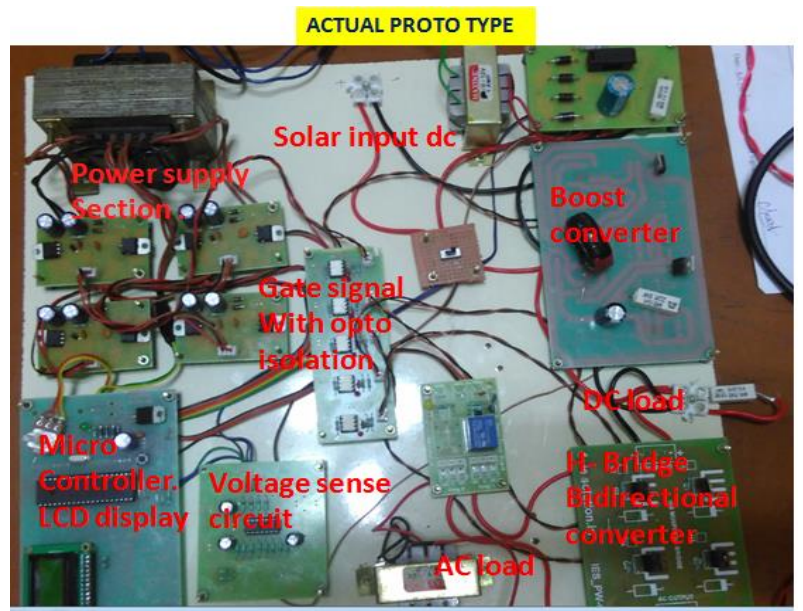

Fig. 21: Actual Complete Proto Type. 
Advantages of Fuzzy control:

It offers a lot a special features that will project this as an advisable choice for most the control systems.

a) Designing and alteration is comfortable. It can control nonlinear systems which are complicated to resolve which acts as feasible system for automation. So it is good control like a human thinking.

b) Fuzzy Logic Controller can be designed even when the understanding of the system is incomplete; when it is difficult to construct the mathematical model of the system.

c) Fuzzy Logic Controller is easier to prototype \& implement for most system without any modification.

\section{Conclusion}

Optimization of DC bus voltage regulation and maintaining of availability of DC bus voltage using alternate input sources of solar and electrical energy with grid connected single phase bi-directional converter has been studied and presented in this paper. A new method of improving dc bus voltage regulation using combination of MPPT with Fuzzy control has been studied by applying it for buck-boost dc-dc converter and related details are presented. Implementation of Fuzzy control technique using MATLAB simulation tool has been presented in detail. Analysed operation of MOSFET based H-bridge bidirectional converter in the rectification mode using wide AC input voltage variation by operating it as boost rectifier using MATLAB simulation tool and presented its functionality along with input and output parameter waveforms. Change over from solar input to AC grid input and vice-versa to maintain dc bus voltage has been studied and explained in detail Complete actual proto type hardware along with software design has been made and verified its functionality.

\section{References}

[1] R.H. Lasseter, "MicroGrids," in Proc. IEEE Power Eng. Soc. Winter Meeting, voU, pp.305-308, 2002

[2] T. Vigneysh, N. Kumarappan and R. Arulraj, "Operation and control of wind/fuel cell based hybrid microgrid in grid connected mode", in Proc. In!. Multi-Conference in Automation, Computing, Communication, Control and Compressed Sensing (iMac4s), pp.754-758, 2013.

[3] C. Wang and M.H. Nehrir, "Power management of a stand-alone windlphotovoltaic/fuel cell energy system", IEEE Trans. Energy Conv., vo1.23, no.3, pp.957-967, 2008.

[4] M.E. Ropp and S. Gonzalez "Development of a MATLAB/Simulink model of a single-phase grid-connected photovoltaic system", IEEE Trans. Energy Conv., vo1.24, no.1, pp.195-202, 2009.

[5] A. Al Nabulsi, A. El Nosh, A. Ahli, M. Sulaiman, and R. Dhaouadi, "Efficiency optimization of a 150W PV system using dual axis tracking and MPPT,' in Proc. IEEE ENERGYCON'10, Bahrain, pp. 400405 .

[6] Yilmaz, M.; Krein, P.T., "Review of Battery Charger Topologies, Charging Power Levels, and Infrastructure for Plug-In Electric and Hybrid Vehicles," Power Electronics, IEEE Transactions on , vol.28, no.5, pp.2151,2169, May 2013.

[7] R. Sioshansi and P. Denholm,"Emissions Impacts and Benefits of Plug- In Hybrid Electric Vehicles and Vehicle-to-Grid Services," Environmental Science \& Technology, vol. 43, no. 4, pp. 1199-204, Feb. 2009.

[8] C. Thomas,'Fuel Cell and Battery Electric Vehicles Compared," International Journal of Hydrogen Energy, p. 262512, 2009.

[9] M. Yilmaz and P. T. Krein, "Review of the Impact of Vehicle-toGrid Technologies on Distribution Systems and Utility Interfaces,' IEEETransactions on Power Electronics, vol. 28, no. 12, pp. 5673 5689, Dec. 2013.

[10] Mischinger, S.; Hennings, W.; Strunz, K., "Integration of surplus wind energy by controlled charging of electric vehicles," Innovative Smart Grid Technologies (ISGT Europe), 2012 3rd IEEE PES International Conference and Exhibition on, vol., no., pp.1, 7, 14-17 Oct. 2012.

[11] Kramer, B.; Chakraborty, S.; Kroposki, B.,"A review of plug-in vehicles and vehicle-to-grid capability," Industrial Electronics, 2008.
IECON 2008. 34th Annual Conference of IEEE , vol., no. pp.2278,2283, 10-13 Nov. 2008

[12] Pahlevaninezhad, M.; Das, P.; Drobnik, J.; Jain, P.K.; Bakhshai, A. "A New Control Approach Based on the Differential Flatness Theory for an AC/DC Converter Used in Electric Vehicles," Power Electronics, IEEE Transactions on , vol.27, no.4, pp.2085,2103, April 2012.

[13] Sebastian, J.; Lamar, D.G.; Rodriguez, A.; Arias, M.; Fernandez, A., "On the Maximum Bandwidth Attainable by Power Factor Correctorswith a Standard Compensator," Applied Power Electronics Conference and Exposition, 2009. APEC 2009. Twenty-Fourth Annual IEEE, vol., no., pp.1872, 1878, 15-19 Feb. 2009.

[14] Prodic, A.; Jingquan Chen; Maksimovic, D.; Erickson, R.W., "Selftuning digitally controlled low harmonic rectifier having fast dynamic response," Power Electronics, IEEE Transactions on , vol.18, no. 1 , pp.420,428, Jan 2003

[15] Eren, S.; Pahlevaninezhad, M.; Bakhshai, A.; Jain, P.,"An Adaptive Droop DC-Bus Voltage Controller for a Grid-Connected Voltage Source Inverter with LCL Filter," Power Electronics, IEEE Transactions on, vol.PP, no.99, pp.1, 2014.

[16] Prodic, A.; Maksimovic, D.; Erickson, R.W.,'Dead-zone digital controllers for improved dynamic response of low harmonic rectifiers," Power Electronics, IEEE Transactions on, vol.21, no.1, pp.173, 181, Jan. 2006.

[17] Pahlevaninezhad, M.; Das, P.; Drobnik, J.; Jain, P.K.; Bakhshai, A.,"A Novel ZVZCS Full-Bridge DC/DC Converter Used for Electric Vehicles," Power Electronics, IEEE Transactions on, vol.27, no.6, pp.2752, 2769, June 2012.

[18] Krismer, F.; Kolar, J.W.,'Efficiency-Optimized High-Current Dual Active Bridge Converter for Automotive Applications," Industrial Electronics,IEEE Transactions on , vol.59, no.7, pp.2745,2760, July 2012. 